\title{
Accelerated ageing of polylactide in aqueous environments: Comparative study between distilled water and seawater
}

\author{
Morgan Deroiné ${ }^{a}$, Antoine Le Duigou ${ }^{a}$, Yves-Marie Corre ${ }^{a}$, Pierre-Yves Le Gac ${ }^{b}$, Peter Davies ${ }^{b}$, \\ Guy César ${ }^{c}$, Stéphane Bruzaud ${ }^{\mathrm{a}, *}$ \\ a Laboratoire d'Ingénierie des Matériaux de Bretagne (LIMATB), Université de Bretagne-Sud, Rue de Saint \\ Maudé, 56321 Lorient, France \\ ${ }^{b}$ IFREMER, Marine Structures Group, Centre de Bretagne, BP 70, 29280 Plouzané, France \\ ${ }^{c}$ SERPBIO, Université de Bretagne-Sud, Rue de Saint Maudé, 56321 Lorient, France
}

*: Corresponding author : Stéphane Bruzaud, tel.: +332 97874584 ; fax: +33 297874588 ; email address :

stephane.bruzaud@univ-ubs.fr

\begin{abstract}
:
Pollution of nature by plastics is a major environmental problem and the challenge for the future is to manage the lifetime of polymers better. The aim of this study is to establish a baseline on degradation mechanism and degradation kinetics for lifetime prediction of polylactide (PLA) in a marine environment. The ageing of PLA was accelerated by raising temperature in distilled water, filtered and renewed seawater and natural seawater. Samples were immersed in distilled water for six months at different temperatures $\left(25,30,40\right.$ and $\left.50^{\circ} \mathrm{C}\right)$ in order to evaluate the influence of temperature on PLA degradation kinetics and to predict lifetime. Then, samples were immersed in seawater both in the laboratory and at sea, in order to compare the effects of environment, marine organisms and salt, on degradation. The different degradation steps were followed by gravimetry, tensile tests, scanning electron microscopy (SEM), steric exclusion chromatography (SEC) and differential scanning calorimetry (DSC). In distilled water, accelerated ageing of PLA is complex with deviation from Fickian behaviour at higher temperature. Moreover, immersion in distilled water induces morphological changes, in particular holes, which are absent in seawater at $40^{\circ} \mathrm{C}$ for the same immersion time. Indeed, seawater has little impact on the diffusion kinetics but affects $M_{\infty}$ values, which are slightly lower compare to the distilled water uptake.
\end{abstract}

Keywords : PLA ; accelerated ageing ; hydrothermal ageing ; degradation

\section{Introduction}

World consumption of polymers has increased exponentially since the nineteen fifties. Polymers are used in many areas, particularly in the packaging industry. Indeed, they have many advantages like light weight, low cost and formability. However, from a life cycle point of view, they also have several drawbacks. First, they are mainly based on non-renewable resources and their price is very dependent on oil prices. Then, polymer materials have a rather short period of use, especially in the packaging 
sector. This implies high volumes of waste, whose handling is far from optimised. Nowadays, plastics which are not incinerated, landfilled or recycled are found in nature polluting for example the seas [1] and the oceans [2] and [3]. It is estimated that $80 \%$ of waste from land activity is carried by winds and rivers, the rest is derived from marine activity. The accumulation and progressive fragmentation of plastic waste lead to dramatic consequences for marine wildlife [4], [5] and [6], slowly becoming dangerous for humans, who are at the end of the marine food chain. That is why in recent years biobased and biodegradable polymers, such as polylactide (PLA), polyhydroxyalkanoates (PHA) or thermoplastic starch (TPS), have appeared as an alternative solution in order to solve these problems. PLA is one of biopolymers which receive, currently, the most attention in the research community. PLA is synthesized by ring-opening polymerization from a cyclic monomer (lactic acid), which is produced from renewable 
resources (corn, starch...). Much attention has been paid on PLA because of their wide range in many applications like packaging [7] or biomedical for suture material or drug release delivery systems [8]. Indeed, PLA offers good mechanical properties, availability, thermoplastic processing capacity [9], the ability to biodegrade under specific conditions [1012] and can have a favorable life cycle assessment compared to conventional polymers [13]. One of the limits remains its poor thermal stability, together with low tenacity and the relative lack of knowledge of its lifetime and degradation behaviour in aqueous environments, and more specifically in the marine environment.

Taib et al. [14] studied ageing of PLA immersed in distilled water at room temperature for 2 months, while Yew et al. [15] followed the degradation at $30^{\circ} \mathrm{C}$ in water (the authors do not detail the nature of water) for 1 month. The latter measured a water absorption of approximately $1 \%$ and showed that the kinetics of water absorption followed Fick's law. They also observed a decrease in stress at break of $30 \%$ after only one month. Berthé et al. [16] determined a $60 \%$ loss for the strain at break after 10 days of ageing at $65^{\circ} \mathrm{C}$ in the presence of $100 \%$ relative humidity $(\mathrm{RH})$.

PLA ageing was also investigated in seawater at $25^{\circ} \mathrm{C}$, and the degradation was insignificant even after immersion for 10 weeks [17,18]. In the same way, Zenkiewicz et al. [10] did not detect large modifications after a 9 week immersion time. Natural ageing of polymers is characterized by slow degradation kinetics and temperature is a parameter frequently employed to accelerate ageing [19]. Accelerated ageing of PLA for 3 months at two different temperatures $\left(20\right.$ and $\left.40^{\circ} \mathrm{C}\right)$, revealed a decrease of almost $50 \%$ of molecular weight after 3 months at $40^{\circ} \mathrm{C}$ in seawater [20].

Most of the articles available in the published literature deal with short term immersion (less than 100 days). Very few compare different ageing environments and accelerated ageing of PLA is also poorly studied. In the present study, ageing of PLA is investigated in several 
aqueous environments over a period of 180 days: distilled water, renewed seawater and natural seawater. Ageing time was accelerated by temperature and the degradation was followed by gravimetry, tensile tests, SEM, SEC and DSC.

The aim of this study is to establish a baseline for degradation mechanisms and degradation kinetics in order to make lifetime predictions of polylactide behaviour in seawater. This approach, based on an Arrhenius law, uses macroscopic indicators such as elongation at break [21] or the stress at break [22]. In order to use this approach natural and accelerated ageing should lead to the same microstructural changes, and there must be a single degradation process characterized by an activation energy, $E_{a}$, which is constant over the temperature range studied. This methodology, using accelerating ageing of PLA, will be discussed throughout this study and some limits of the approach will be highlighted.

\section{Experimental}

\subsection{Materials}

The polylactide (PLA) studied was a commercial grade (7001D) supplied by NatureWorks ${ }^{\circledR}$ (USA) with a D-lactide content of $4.4 \% \pm 0.5$ (supplier's data). The material has an average molecular weight $\bar{M}_{\mathrm{n}}=75000 \mathrm{~g} \cdot \mathrm{mol}^{-1}$.

\subsection{Preparation of tensile samples}

PLA pellets were dried at $50^{\circ} \mathrm{C}$ under vacuum for $24 \mathrm{~h}$ before processing. For the preparation of dog-bone specimens, pellets were injected using a Battenfeld HM 80/120 press. All parameters were kept constant during the injection molding process. The hopper temperature was $190^{\circ} \mathrm{C}$ and the profile was the following: $190-190-190-190^{\circ} \mathrm{C}$. The injection pressure was 1500 bars and the mould temperature was kept at $40^{\circ} \mathrm{C}$. PLA was injected in a mold designed to produce normalized specimens, $180 \times 10 \times 4 \mathrm{~mm}$ geometry (sample $1 \mathrm{~A}$ according to $\mathrm{NF}$ EN ISO 527). 


\subsection{Ageing conditions}

Ageing tests were performed under several conditions: distilled water, filtered and renewed seawater and natural seawater. First, some PLA samples were immersed in distilled water in different containers (volume $25 \mathrm{~L}$ ) at $25,30,40$ and $50^{\circ} \mathrm{C}$. The use of a higher temperature is not representative because PLA will be in another crystalline configuration. In a previous study at $60^{\circ} \mathrm{C}$, results indicated that degradation at this temperature close to the $\mathrm{T}_{\mathrm{g}}$, is very rapid [20]. The distilled water was renewed each week; then, $\mathrm{pH}$ influence can be considered as negligible. A few drops of bactericide were added in the bath to prevent bacterial growth. Then, another series of PLA samples were immersed in baths (volume $60 \mathrm{~L}$ ) at 25 and $40^{\circ} \mathrm{C}$, with seawater pumped from the Brest estuary (France), filtered and continuously renewed. Water and salt effects were studied. Indeed, the average ocean salinity is $35 \mathrm{~g} / \mathrm{L}$ and the most abundant dissolved ions in seawater are sodium, chloride, magnesium, sulphate and calcium [23]. In parallel, natural ageing tests were also performed in the Lorient harbour (France) in order to compare the results and an effect of marine bacteria is then added. Seawater temperatures during the study, from March to September 2012, were approximately between 11 and $19^{\circ} \mathrm{C}$.

\subsection{Characterization techniques}

\subsubsection{Water uptake}

At selected immersion times, dog-bone specimens immersed in water were removed, washed several times with distilled water, wiped and weighed at room temperature $\left(23^{\circ} \mathrm{C}\right.$ and $\mathrm{RH}=$ $50 \%$ ) on a weighing machine with a precision of $0.1 \mathrm{mg}$. The percentage gain at any time $t$, $\mathrm{M}_{\mathrm{t}}$ as a result of water uptake, was determined by Eq. (1):

$$
M_{t}(\%)=\frac{W_{t}-W_{0}}{W_{t}} \times 100
$$


where $\mathrm{W}_{0}$ and $\mathrm{W}_{\mathrm{t}}$ denote, respectively, weight of dry material (the initial weight of materials prior to water exposure) and material weight after exposure to water. The maximum moisture absorption, $\mathrm{M} \infty$, is calculated as an average value of several consecutive measurements that show very little variation of water absorption. The weight gain resulting from moisture absorption can be modelled in terms of two parameters, the diffusion coefficient $\mathrm{D}$ and the maximum moisture content Mœ, are given by Fick's first law in Eq. (2):

$$
\frac{M_{t}}{M_{\infty}}=1-\frac{8}{\pi^{2}} \sum \frac{1}{(2 i+1)^{2}} \exp \left(-\frac{D(2 i+1)^{2} \pi^{2} t}{e^{2}}\right)
$$

where e is the thickness of the sample. D can be calculated from the initial linear portion of the absorption curve. For $M_{t} / M_{\infty} \leq 0.5$ the function $\mathrm{M}_{\mathrm{t}}=\mathrm{f}(\sqrt{\mathrm{t}})$ is linear and the Fickian diffusion coefficient D is determined by Eq. (3):

$$
D=\frac{\pi}{16} \frac{e^{2}}{t}\left(\frac{M_{t}}{M_{\infty}}\right)^{2}
$$

Commonly, this equation is used for square specimen dimension. A correction factor is needed to account for the finite width, w, and length, h, of the sample compared to its thickness, d, using Eq. (4) [24]:

$$
D c=D\left(1+\frac{d}{h}+\frac{d}{w}\right)^{-2}
$$

where Dc is the corrected diffusion coefficient.

\subsubsection{Mechanical tests}

Static tensile tests were carried out in an environmentally controlled laboratory, according to ISO $527\left(23^{\circ} \mathrm{C}\right.$ and $50 \%$ relative humidity) on an MTS Synergie RT1000 testing machine. The loading speed was $1 \mathrm{~mm} / \mathrm{min}$. An MTS extensometer was used to measure strain, over a $25 \mathrm{~mm}$ gauge length. Two types of tests were performed, one on wet specimens, one on dry. 
At least five specimens were tested for each condition, and the results were averaged arithmetically.

\subsubsection{Scanning electron microscopy (SEM)}

Microscopy analyses were performed with a Jeol JSM 6460LV scanning electron microscope to examine the fracture surface of the PLA samples. Prior to observation, the fracture surfaces of unaged PLA and aged PLA were prepared by fracture in liquid nitrogen. Then, specimens were sputter-coated with a thin gold layer by means of a sputtering apparatus (Edwards Sputter Coater)

\subsubsection{Molecular weight measurement}

Sterical exclusion chromatography (SEC) was used to determine the evolution of molecular weight. The apparatus is equipped with a set of three columns: two ResiPore and one PL gel Mixed C (Polymer Labs.). The detection system is composed of a refractometer and a UV detector. Chloroform was used as eluent with a flow rate of $0.8 \mathrm{~mL} / \mathrm{min}$. The elution profiles were analysed by the Empower GPC module software (Waters). Calculations are based on calibration curves obtained from polystyrene standards ranging from $200 \mathrm{~g} / \mathrm{mol}$ up to $6 \times 106$ $\mathrm{g} / \mathrm{mol}$. The weight-average molecular weight $\left(\bar{M}_{\mathrm{w}}\right)$ and number-average molecular weight $\left(\bar{M}_{\mathrm{n}}\right)$ are obtained from the SEC analysis. The polydispersity index (PI) was calculated as $\bar{M}_{w} / \bar{M}_{n}$. Moreover, in order to analyse an autocatalysis, the average number of random chain scissions per unit mass, $\mathrm{n}_{\mathrm{t}}$, was calculated by Eq. (5) [25]:

$$
n_{t}=\frac{1}{\bar{M}_{n_{t}}}-\frac{1}{\bar{M}_{n_{0}}}
$$

where $\bar{M}_{n t}$ and $\bar{M}_{n o}$ are the number-average molecular weight at time $\mathrm{t}$ and at initial time, respectively.

\subsubsection{Thermal analysis}


Differential scanning calorimetry (DSC) analysis was performed on samples of about $10 \mathrm{mg}$, in standard aluminium pans, using Mettler-Toledo DSC882 equipment under nitrogen atmosphere. Data were recorded at a heating rate of $20^{\circ} \mathrm{C} / \mathrm{min}$. The samples were heated from 20 to $200^{\circ} \mathrm{C}$ and kept at $200^{\circ} \mathrm{C}$ for 3 minutes. After that, the samples were cooled to $-20^{\circ} \mathrm{C}$ and finally a second heating scan was performed from -20 to $200^{\circ} \mathrm{C}$ to distinguish the reversible effects from permanent changes. The crystallinity of PLA was determined by Eq. (6):

$$
\chi=\frac{\Delta H_{m}-\Delta H_{c c}}{\Delta H_{100 \%}}
$$

where $\Delta \mathrm{H}_{\mathrm{m}}$ and $\Delta \mathrm{H}_{\mathrm{cc}}(\mathrm{J} / \mathrm{g}$ of polymer) are the melting enthalpy and the cold crystallization enthalpy, respectively. $\Delta \mathrm{H}_{100 \%}$ is the melting enthalpy for PLA of $100 \%$ crystallinity, taken to be $93.1 \mathrm{~J} / \mathrm{g}[9]$.

\section{Results and discussion}

\subsection{Accelerated ageing in distilled water}

\subsubsection{Water uptake}

Fig. 1 shows the weight gain of PLA as a function of $t^{1 / 2}$ (expressed in $\mathrm{H}^{1 / 2}$ ) at different immersion temperatures. An initial linear relationship between water uptake and square root of time is observed at 25 and $30^{\circ} \mathrm{C}$, followed by plateau saturation, indicating a typical Fickian behaviour. Data for the saturation plateau at 25 and $30^{\circ} \mathrm{C}$, are respectively $0.59 \%$ and $0.62 \%$ (Table 1). These values are a little lower than those found in the literature but diffusion coefficients are similar $[14,15,26]$. PLA grades are not the same and morphology is known to affect the water uptake [27,28]. Processing can also induce morphological changes.

Due to moderate polarity induced by the presence of ester bonds [29], PLA absorbs higher water content than conventional commodity polymers such as $\mathrm{PP}$ or $\mathrm{PE}(0.2 \%$ at room 
temperature $[24,30]$ ) which are quite hydrophobic, but lower than some polyamides (for polyamide $11, \mathrm{M}_{\infty}$ is around $1.6 \%$ in $\mathrm{pH} 7$ immersion at $\left.50^{\circ} \mathrm{C}[31]\right)$.

\section{Figure 1 and Table 1}

At $40^{\circ} \mathrm{C}$, a deviation from Fickian behavior is observed. Indeed, after a plateau similar to those observed at lower temperatures, i.e. 25 and $30^{\circ} \mathrm{C}$, around $0.76 \%$, a sharp increase in water absorption occurs after about 100 days. This trend is also observed at $50^{\circ} \mathrm{C}$, but occurs earlier (after 15 days). This increase, already observed in the literature, indicates degradation within the polymer and is attributed to several phenomena. First, it may be due to the generation of holes in the PLA associated with osmotic cracking phenomena [16,32]. The increase may also be linked with the creation of diffusion paths induced by cracks [33]. Another explanation could be the hydrolysis process products such as carboxyl groups, which have a strong water affinity [34].

Using Eq. 3, Fickian diffusion coefficients were calculated (Table 1), based on the hypothesis that the experimental plateau observed is the saturation plateau. A linear relation $\left(\mathrm{R}^{2}=0.98\right)$ is noted between $\operatorname{lnD}$ and the inverse of temperature (Fig. 2), suggesting that these coefficients obey an Arrhenius law (Eq. 7):

$$
D=D_{0} \exp \left(-\frac{E_{a}}{R T}\right)
$$

\section{Figure 2}

The activation energy $E_{a}$ is obtained from the slope of the linear fitting of $\operatorname{lnD} v \mathrm{vs}^{-1}$ and is estimated at $30 \mathrm{~kJ} / \mathrm{mol}$. Very few published values are available but $\mathrm{E}_{\mathrm{a}}$ has been found to range from 40 to $80 \mathrm{~kJ} / \mathrm{mol}$ [35]. This slightly lower $E_{a}$ value could be explained by several reasons: the different kinds of aqueous environments, the grade of PLA used or the processing conditions which modify the polymer morphology. In distilled water, the absence of many components such as mineral salts could facilitate the diffusion of water within the matrix and the energy required is therefore lower. 
These results indicate that temperature can be used within a limited range for accelerated ageing of PLA, but lifetime prediction is more difficult. One of the initial assumptions for accelerated aging is not respected because structural changes occur at higher temperature, despite the narrow temperature range.

\subsubsection{Mechanical properties}

Tensile tests were carried out on the aged PLA samples in the wet state and after drying. Fig. 3 shows the mechanical behaviour of PLA samples after 6 months in distilled water at 25, 30 and $40^{\circ} \mathrm{C}$ and after 15 days at $50^{\circ} \mathrm{C}$. The degradation rate of PLA at $50^{\circ} \mathrm{C}$ is very fast, and after one month, tensile tests were not possible due to the very brittle nature of the aged samples.

\section{Figure 3}

An initial elastic linear behaviour is observed, whatever the ageing temperature. After 6 months of immersion at $25^{\circ} \mathrm{C}$, ductility increases for wet PLA (Fig. 3a.). After drying, behaviour returns to the initial state. At 30 and $40^{\circ} \mathrm{C}$ after 6 months, PLA is less ductile in wet tests and the strain at break decreases. However, in the dry state, PLA recovers partially its initial properties at $30^{\circ} \mathrm{C}$ but becomes completely brittle at $40^{\circ} \mathrm{C}$. These variations confirm the irreversible nature of the degradation. At $50^{\circ} \mathrm{C}$, all changes are intensified. After only 15 days, ductility increases and failure strain exceeds $20 \%$. In the dry state, a significant decrease in stress at break is observed and brittle behaviour is noted.

The evolutions of global dry mechanical properties as a function of the temperature and immersion time are presented in Fig. 4 and property percentage losses are shown in Table 2. As shown in Fig. 4a, at 25 and $30^{\circ} \mathrm{C}$ the stress at break remains constant during ageing. At $25^{\circ} \mathrm{C}$, the increase in strain is observed after 2 months of immersion and is constant over time (Fig. 4b). Nevertheless, at $30^{\circ} \mathrm{C}$, the increase in failure strain is significant after 1 month of immersion (+47\%) but drops after 6 months $(-42 \%)$. After 6 months at $40^{\circ} \mathrm{C}$, the stress and 
the strain at break were greatly reduced, -85 and $-92 \%$ respectively, with a sudden drop observed in the failure stress after 4 months (Fig. 4a). For these three temperatures and after 6 months, the Young's modulus increases compared to the initial properties but values remain relatively similar. After only 15 days at $50^{\circ} \mathrm{C}$, the stress and the strain at break decrease, with a loss of $12 \%$ and $50 \%$ respectively and Young's modulus remains quite constant.

\section{Figure 4}

These mechanical results show a reversible degradation at short times and at lower temperature. Indeed, the plasticization of the PLA by water is reversible [7] and the loss of properties is quite small after 6 months at $25^{\circ} \mathrm{C}$. Temperature increase promotes a premature loss of properties, which could be linked with water uptake (Fig. 5). A quasi-linear relationship can be found below 1\%, weight gain for all temperatures. From this point on, the phenomena become irreversible and the ageing temperature clearly accelerates the PLA degradation. Loss of linearity between water uptake and stress at break is observed at 40 and $50^{\circ} \mathrm{C}$ and this is explained by a different diffusive behaviour. On the Fig. 1, the sudden increasing, after saturation plateau, corresponds to a water uptake threshold. This deviation compared with standard Fickian models leads to a fall of stress at break (Fig. 4b).

\section{Figure 5 and Figure 6}

The SEM images in Fig. 6d reveal the appearance of holes within PLA after 6 months at $40^{\circ} \mathrm{C}$ and this can explain the sudden increase in water uptake observed after 4 months (Fig. 1). It appears here that during hydrolytic degradation the PLA undergoes bulk degradation, as previously noted [36,37]. Indeed, a hydrolysis reaction takes place homogeneously throughout the sample. The formation of lactic acid oligomers, which directly follows from the chain scission, increases the carboxylic acid end groups concentration and then leads to a heterogeneous degradation. Oligomer products near the surface are rapidly evacuated while those formed in the bulk stay inside, and promote autocatalysis in the heart of the sample. 
Modeling to develop a lifetime prediction will be complex because degradation becomes heterogeneous. Moreover, degradation kinetics differs at higher temperature, despite the narrow range of temperature used.

\subsubsection{Molecular weight analysis}

Measurements of molecular weight enable permanent changes due to chemical ageing to be detected and can be directly linked with dry mechanical properties. Table 3 shows the evolution of molecular weights of PLA samples as a function of ageing time and temperature.

\section{Table 3}

A reduction of $\bar{M}_{\mathrm{n}}$ by $10 \%$ and $15 \%$ is observed at 25 and $30^{\circ} \mathrm{C}$ respectively after 180 days' immersion, indicating a small proportion of chain cleavage. This confirms the results obtained using tensile tests. At $40^{\circ} \mathrm{C}, \bar{M}_{\mathrm{n}}$ decreases with the immersion time with a drop of $65 \%$ after 6 months. After only one month at $50^{\circ} \mathrm{C}, \bar{M}_{\mathrm{n}}$ is reduced by $60 \%$ compared to the initial value. Polydispersity index values (Table 3) also provide information on the distribution of chain lengths and on the chain cleavage mechanism. At $25^{\circ} \mathrm{C}$, the evolution of the polydispersity index is negligible, while a slight decrease is observed at $30^{\circ} \mathrm{C}$. At $40^{\circ} \mathrm{C}$ after 6 months and at $50^{\circ} \mathrm{C}$ after only one month, the polydispersity index decreases significantly, indicating different chain cleavage kinetics, which will make modelling difficult. For temperatures above $30^{\circ} \mathrm{C}$, the random chain cleavages are caused by the hydrolysis of ester functions introducing a polymer weakening, as discussed previously.

Fig. 7 represents the average number of random chain scission $\left(n_{t}\right)$ per unit mass for PLA as a function of immersion at different temperatures (Eq. 5). No change is observed at 25 and $30^{\circ} \mathrm{C}$. At 40 and $50^{\circ} \mathrm{C}$, the increasing $\mathrm{n}_{\mathrm{t}}$ value can be explain by an autocatalytic process linked to the formation of lactic acid oligomers, which directly result from these chain scission processes, increasing the concentration of carboxylic acid end groups in the medium. 
The catalysis degradation is confirmed by results obtained by SEM (Fig. 6d) and by the increase of water uptake.

\section{Figure 7}

The formation of lactic acid oligomer, estimated by determination of acid group contents contained in the PLA samples after 6 months' immersion at 25,30 and $40^{\circ} \mathrm{C}$ and after only 1 month at $50^{\circ} \mathrm{C}$, confirmed these results (not shown here). At 25 and $30^{\circ} \mathrm{C}$, no significant difference was observed in the acid group content for unaged PLA or aged PLA. However at $40^{\circ} \mathrm{C}$, greatly significant increase was noted, by a factor 3 after 6 months' immersion, confirming the higher degradation rate observed with the SEC results. At $50^{\circ} \mathrm{C}$, the increase in the acid group amount is similar to that measured for the sample aged at $40^{\circ} \mathrm{C}$ but for a much shorter immersion time (i.e. after 1 month).

All the results obtained from molecular weights, average number of random chain scission and acid group content highlight a progressive acceleration in the PLA degradation up to a temperature of $40^{\circ} \mathrm{C}$, which is followed by a strong acceleration when the ageing temperature reaches a value close to $50^{\circ} \mathrm{C}$. The water uptake results correlate with these observations. Moreover, the hydrolytic degradation of PLA is a self-catalysed process when temperature increases. Carboxylic acid chains formed in the bulk facilitate autocatalysis in the heart of the sample. This is a further complication for a prediction tool [38].

\subsubsection{Thermal properties}

Table 4 summarizes the thermal properties of PLA after 6 months at 25,30 and $40^{\circ} \mathrm{C}$, and after 1 month at $50^{\circ} \mathrm{C}$, obtained by DSC first and second heating scans.

\section{Table 4}

At 25 and $30^{\circ} \mathrm{C}$ after 6 months in distilled water, the melting and cold crystallization temperatures remain constant during the first heating while a slight reduction of glass transition is observed. For the second heating, the $T_{g}$ values decrease slightly which confirms 
the reversible degradation for long time immersion. At 40 and $50^{\circ} \mathrm{C}$, all the transition temperatures decrease significantly. These lower temperatures may make residual stress relaxation easier and lead to microstructural changes which can also facilitate the increase of water uptake [39]. The melting enthalpy shows a clear increase, for example at $40^{\circ} \mathrm{C}$ from 2 to $37 \mathrm{~J} / \mathrm{g}$. This can be related to the significant decrease in the PLA molecular weights under these conditions, as shown by SEC. The remaining PLA chains then have higher mobility and they can reorganize themselves more easily which leads to an increase of the melting enthalpy and degree of crystallinity [16,40]. In addition, after 1 month of immersion at $50^{\circ} \mathrm{C}$, a duplication of the melting peak appears (not shown here), which is a phenomenon already observed in the literature and corresponds to the formation of some oligomers during degradation and development of different crystal populations [41,42]. Moreover, the disappearance of a cold crystallization peak at $50^{\circ} \mathrm{C}$ after 30 days can also be ascribed to the increasing crystallinity of PLA with degradation time [43]. We can assume that macromolecular chains are less mobile in these conditions and this may suggest that crystallization threshold is reached after PLA ageing for 30 days at $50^{\circ} \mathrm{C}$.

The evolution of the global crystallinity $\left(\chi_{c}\right)$ of the PLA chains during hydrolysis can be deduced from the evolutions of both $\Delta \mathrm{H}_{\mathrm{cc}}$ and $\Delta \mathrm{H}_{\mathrm{m}}$. Initially, $\chi_{\mathrm{c}}$ is very weak, i.e. between 1 and $2 \%$, indicating a quasi-amorphous structure explaining why PLA is totally transparent before ageing (Fig 8). Based on the first scans, crystallinity increases at all temperatures except at $40^{\circ} \mathrm{C}$. The hydrolytic chain cleavage proceeds preferentially in amorphous regions, but for long ageing times crystalline lamellae may also be affected by the hydrolysis, leading therefore to a decrease of the crystallinity ratio [25]. During the second heating, crystallinity remains constant. Indeed, PLA is totally melted after the first scan and there is no recrystallization during cooling. However, melting and cold crystallisation enthalpies 
regularly increase with the temperature of immersion, attributed to the higher molecular mobility of shorter chains.

Moreover, an increase in the relative opacity of samples with aging time is observed (Fig. 8a), caused by a molecular reorganization induced by chain scission [44], and confirmed by SEC and DSC results. At $25^{\circ} \mathrm{C}$ and after 6 months, samples maintain the same appearance as before ageing. These results suggest that the degradation is very low at this temperature and confirm the lack of structural changes. Some modifications in the visual aspects begin for the PLA aged after 6 months at $30^{\circ} \mathrm{C}$. Sample whitening in the distilled water is clearly accentuated with ageing time and temperature.

\section{Figure 8}

In this section, we have shown that hydrolytic degradation of PLA even in distilled water is a complex mechanism, due to the polymer morphology and its temperature sensitivity. This is not in itself surprising, as PLA is a biodegradable polymer under specific conditions [12]. However, after analyzing the effects of distilled water uptake on PLA samples at different temperatures, in order to envisage the use of this polymer in marine applications it is essential to extend this study to examine the influence of the environment. Two ageing temperatures were selected, 25 and $40^{\circ} \mathrm{C}$, and aging in seawater both in the laboratory and at sea has been performed.

\subsection{Influence of seawater ageing}

\subsubsection{Water uptake}

Fig. 9 compares the weight gain of PLA plotted as a function of square root of immersion time (expressed in $\mathrm{H}^{1 / 2}$ ) in natural seawater, in distilled water and renewed and filtered seawater at 25 and $40^{\circ} \mathrm{C}$.

At $25^{\circ} \mathrm{C}$ and under natural conditions, the evolutions of water absorption are very similar (Fickian behavior) to the one at $40^{\circ} \mathrm{C}$ in seawater. The behavior of the PLA aged at $40^{\circ} \mathrm{C}$ in 
seawater differs from distilled water with the sharp increase of water absorption around 120 days. This observation can be correlated with the difference in sample morphology observed in Fig 6c and 6d. The SEM images clearly reveal the appearance of many cavities and holes of different shapes and sizes. The ageing effects are much more pronounced for the PLA samples aged in distilled water, which are characterized by a higher degradation rate, compared to the samples aged in seawater for the same period. The accelerated ageing in seawater could be easier to use in a lifetime prediction of PLA because the structural changes are similar.

The saturation plateau and the diffusion coefficients are lower in seawater than in distilled water (still with the assumption of the intermediate plateau) but we can note they are in the same range (Table 5). Moreover, values in seawater are higher than published values [20]. Regarding the results for the immersion in a natural environment, the value of the plateau is $0.47 \%$ and the diffusion coefficient associated is $0.3710^{-7} \mathrm{~cm}^{2} / \mathrm{s}$ but immersion temperature is lower than in laboratory tests.

\section{Figure 9 and Table 5}

Temperature has an influence on the value of the plateau as it facilitates the water diffusion within the PLA. The marine eco-system has a little impact on the diffusion kinetics but affects the $\mathrm{M}_{\infty}$ value. Different mineral salts present in seawater (around 3.5\%) may explain this difference. Moreover, ageing in seawater is similar to that in distilled water if we consider an immersion inferior at 120 days. Modeling of ageing in seawater, using distilled water, is therefore possible in this time window.

\subsubsection{Mechanical properties}

The influence of immersion in seawater on tensile behavior of PLA specimens after 6 months at 25 and $40^{\circ} \mathrm{C}$ was also investigated, and was compared to the behavior of the specimens aged in distilled water (Fig. 10). 
Figure 10

At 25 and $40^{\circ} \mathrm{C}$, mechanical behaviour is similar for both aging environments. Regarding the evolution of mechanical properties (Table 2), for the strain at break at $25^{\circ} \mathrm{C}$, an increase from 3.4 to $6.9 \%$ is observed after 6 months of immersion in the dry state, this is similar to the results of Le Duigou et al. [20]. At $40^{\circ} \mathrm{C}$, the stress at break of PLA decreases significantly after 6 months' immersion but with a larger reduction in distilled water $(85 \%$ versus $70 \%$ in seawater). The reduction in properties of PLA in sea water, smaller than in distilled water, can be attributed to the difference in water absorption (Fig. 9a) and to the different morphology observed by SEM.

In each immersion medium, the Young's modulus tends to slightly increase with time, this could be explained by an increase in the crystallinity. Considering the natural ageing, PLA properties do not evolve significantly, confirmed by SEM images (Fig. 6b) despite an extremely slow drop in strain at break over time. As a result it will be difficult to establish a correlation with the accelerated test values in order to make a lifetime prediction, even after 6 months of immersion.

Considering the accelerated ageing in seawater and distilled water, the nature of the aqueous medium significantly affects the polymer properties. Degradation is faster in distilled water as has already been noted previously $[45,46]$. Possible reasons are the role of mineral salts which facilitate the diffusion of seawater within the polymer and/or a lower $\mathrm{pH}$ of distilled water, $\approx 6$ against $\approx 8$ for seawater, which can promote hydrolytic degradation [35]. However, despite a more aggressive degradation in distilled water, the ageing temperature appears to be the main parameter affecting the mechanical property changes.

\subsubsection{Molecular weight analysis}

$\bar{M}_{\mathrm{n}}$ and $\bar{M}_{\mathrm{w}}$ of PLA specimens aged in natural conditions do not change significantly after 6 months and the polydispersity index remains constant (Table 6). At $25^{\circ} \mathrm{C}$, slight changes 
occur between both environments with a PI constant. At $40^{\circ} \mathrm{C}, \bar{M}_{\mathrm{n}}$ and $\bar{M}_{\mathrm{w}}$ reductions of 65 and $73 \%$ in distilled water and 75 and $77 \%$ in seawater, are measured respectively. Moreover, there is a difference between the polydispersity index, lower in distilled water, which suggests that kinetics of chain cleavage are different and it this correlates with the lower degradation in seawater. Critical molecular weight, corresponding to an "end of use" criterion, can be determined by plotting the evolution of stress at break versus evolution of molecular weight (not shown here) and is, in each environment, close to $30000 \mathrm{~g} / \mathrm{mol}$.

\section{Table 6}

The evolution of acid values for PLA specimens aged in natural seawater, in renewed seawater and distilled water at 25 and $40^{\circ} \mathrm{C}$ (not shown here), follows the same trends.

\subsubsection{Thermal properties}

Table 7 shows the influence of degradation time on thermal transitions $\left(T_{g}, T_{c}\right.$ and $\left.T_{m}\right)$ as well as enthalpies $\left(\Delta \mathrm{H}_{\mathrm{cc}}, \Delta \mathrm{H}_{\mathrm{m}}\right)$ and crystallinity $\left(\mathrm{X}_{\mathrm{c}}\right)$. Regarding the first heating, for PLA samples aged in natural conditions and at $25^{\circ} \mathrm{C}$ in both environments, the evolution of transition temperatures are almost the same, whatever the immersion medium. For the second heating, a slight decrease in $T_{g}$ is observed while $T_{c c}$ and $T_{m}$ do not evolve, despite a slight increase in enthalpy $\Delta \mathrm{H}_{\mathrm{cc}}$ and $\Delta \mathrm{H}_{\mathrm{m}}$. However, the increase in crystallinity is more important in distilled water.

\section{Table 7}

At $40^{\circ} \mathrm{C}$, the immersion environment appears to have a stronger effect on the thermal properties of PLA. The most critical case is obtained in distilled water with a decrease in $T_{g}$ of about $15^{\circ} \mathrm{C}$ during the first heating, this effect is not observed at the same temperature in the marine environment. This significant variation of $\mathrm{T}_{\mathrm{g}}$ in distilled water can be linked to the water uptake which is more important in distilled water than in seawater (see Fig. 9), inducing an higher plasticizing effect, as already observed by Balzer et al. [47]. Similarly, $\mathrm{T}_{\mathrm{cc}}$ and $\mathrm{T}_{\mathrm{m}}$ 
were greatly reduced after 6 months in distilled water while in seawater, only a decrease of $\mathrm{T}_{\mathrm{cc}}$ is noted. In addition, there is much less difference between the two environments in the second heating because the influence of water on the polymer is removed. Changes observed in Fig. 8b such as the whitening of specimens do not depend on the immersion environment but only the temperature.

\subsection{Prediction of long term immersion behavior}

When immersed in water, PLA first absorbs water with a Fickian behavior up to a maximum water up take of about $0.8 \%$. The presence of this water leads to a plasticization of the polymer, a decrease in $\mathrm{T}_{\mathrm{g}}$ is observed indicating an increase in molecular mobility. This enhancement of molecular motion leads to a large increase in the elongation at break and a decrease of stress at break. A linear relationship between stress at break and water content in PLA can be observed, for a 0 to $1 \%$ water content range. When samples are dried, mechanical behavior is equivalent to that of unaged samples.

However, irreversible degradation also occurs when PLA is immersed in water for longer times or higher temperatures [48]. In fact, at $40^{\circ} \mathrm{C}$ and $50^{\circ} \mathrm{C}$ (for the immersion durations studied here) hydrolysis occurs in the PLA, leading to an irreversible chain scission that induces changes in terms of mechanical behavior and an increase in crystallinity due to a chemi-crystallization process $[48,49]$. Chemi-crystallisation is the phenomenon linking crystallinity and chain scission. Indeed, in semicrystalline polymers the chain scission process occurs only in the amorphous phase by freeing new chain segments which have higher mobility and can reorganize themselves. Irreversible embrittlement of the material is observed when tests are performed in both wet and dry conditions, this is a typical consequence of chain scission mechanisms [20]. Moreover, at the same time as embrittlement, a large water uptake is recorded, corresponding to the observation of holes within the bulk of samples. This 
could be explained by an osmotic process, which has already been observed in other hydrolysable polymers $[16,25,32]$.

These observations suggest that, as long as hydrolytic degradation remains limited, water absorption in PLA can be predicted using a Fickian behavior with a linear Arrhenius law for water diffusion kinetics. Moreover, under these conditions mechanical behavior of the polymer can be assessed using a linear relationship between water uptake and stress at break. When hydrolysis occurs, life time prediction is no longer straightforward and competing factors including autoacceleration and osmotic degradation will require more detailed analysis.

\section{Conclusions}

In this work, accelerated ageing of PLA has been performed in different aqueous environments (distilled water, filtered and renewed seawater in the laboratory, and natural seawater at sea). Ageing is accelerated by the temperature in order to establish a baseline for PLA lifetime predictions in a marine environment.

First, the water uptake within PLA in distilled water is temperature dependant and follows Fickian behaviour at 25 and $30^{\circ} \mathrm{C}$ while a deviation from Fickian behaviour is noted at 40 and $50^{\circ} \mathrm{C}$. Using the intermediary plateau to determine diffusion coefficients, a linear relation appears between $\log \mathrm{D}$ and the inverse of temperature. However, SEM images (particularly figure $6 \mathrm{~d}$ ), show important structural changes with temperature. The loss of linearity between mechanical properties and water uptake reveal that degradation mechanisms are modified above $40^{\circ} \mathrm{C}$, as confirmed by SEC and DSC, and underline the complexity of lifetime prediction for this material.

The influence of the environment has also been shown and the degradation rate is faster in distilled water than in seawater. One reason is the lack of mineral salts which facilitates the 
diffusion of water within the polymer. Seawater uptake, following Fickian behaviour, has little influence on the diffusion kinetics but affects $\mathbf{M}_{\infty}$ values, which are slightly lower compared to the distilled water uptake values. Concerning mechanical properties after aging at $40^{\circ} \mathrm{C}$ in the two environments, PLA is degraded after 6 months in both but SEM images show different degrees of degradation.

The initial aim of this work was to develop a lifetime prediction methodology for PLA in the marine environment. Data acquired during this study do not yet allow such predictions to be made, as the limited temperature range which allows acceleration without introducing new damage mechanisms does not allow a correlation with marine conditions. In one sense this is encouraging, as it shows that PLA can be used for at least 6 months in seawater with little degradation. Further work is underway to extend the study, in particular by the use of thin film specimens which should enable more rapid saturation to be attained and core/surface differences to be limited.

Acknowledgements: The authors thank the SERPBIO association for financial support. The authors are also pleased to express their grateful acknowledgements to Dr. Jean-Luc Audic, Anthony Magueresse and Gustavo Mendez for their help in the experimental work.

\section{References}

[1] Galgani F, Jaunet S, Campillo A, Guenegen X, His E. Distribution and abundance of debris on the continental shelf of the north-western Mediterranean Sea. Mar Pollut Bull 1995;30:713-717.

[2] Barnes DKA, Walters A, Gonçalves L. Macroplastics at sea around Antarctica. Mar Environ Res 2010;70:250-252.

[3] Pichel WG, Churnside JH, Veenstra TS, Foley DG, Friedman KS, Brainard RE. Marine debris collects within the North Pacific Subtropical Convergence Zone. Mar Pollut Bull 2007;54:12071211.

[4] Ryan PG. Seabirds indicate changes in the composition of plastic litter in the Atlantic and southwestern Indian Oceans. Mar Pollut Bull 2008;56:1406-1409.

[5] Boerger CM, Lattin GL, Moore SL, Moore CJ. Plastic ingestion by planktivorous fishes in the North Pacific Central Gyre. Mar Pollut Bull 2010;60:2275-2278.

[6] Avery-Gomm S, O'Hara PD, Kleine L, Bowes V, Wilson LK, Barry KL. Northern fulmars as biological monitors of trends of plastic pollution in the eastern North Pacific. Mar Pollut Bull 2012;64:1776-1781. 
[7] Holm VK, Ndoni S, Risbo J. The Stability of Poly(lactic acid) Packaging Films as Influenced by Humidity and Temperature. J Food Sci 2006;71:E40-E44.

[8] Ikada Y, Tsuji H. Biodegradable polyesters for medical and ecological applications. Macromol Rapid Commun 2000;21:117-132.

[9] Lim L-T, Auras R, Rubino M. Processing technologies for poly(lactic acid). Prog Polym Sci 2008;33:820-852.

[10] Żenkiewicz M, Malinowski R, Rytlewski P, Richert A, Sikorska W, Krasowska K. Some composting and biodegradation effects of physically or chemically crosslinked poly(lactic acid). Polym Test 2012;31:83-92.

[11] Cadar O, Paul M, Roman C, Miclean M, Majdik C. Biodegradation behaviour of poly(lactic acid) and (lactic acid-ethylene glycol-malonic or succinic acid) copolymers under controlled composting conditions in a laboratory test system. Polym Degrad Stab 2012;97:354-357.

[12] Itävaara M, Karjomaa S, Selin J-F. Biodegradation of polylactide in aerobic and anaerobic thermophilic conditions. Chemosphere 2002;46:879-885.

[13] Hermann BG, Debeer L, De Wilde B, Blok K, Patel MK. To compost or not to compost: Carbon and energy footprints of biodegradable materials' waste treatment. Polym Degrad Stab 2011;96:1159-1171.

[14] Taib RM, Ramarad S, Ishak ZAM, Todo M. Properties of kenaf fiber/polylactic acid biocomposites plasticized with polyethylene glycol. Polym Compos 2010;31:1213-1222.

[15] Yew GH, Mohd Yusof AM, Mohd Ishak ZA, Ishiaku US. Water absorption and enzymatic degradation of poly(lactic acid)/rice starch composites. Polym Degrad Stab 2005;90:488-500.

[16] Berthé V, Ferry L, Bénézet JC, Bergeret A. Ageing of different biodegradable polyesters blends mechanical and hygrothermal behavior. Polym Degrad Stab 2010;95:262-269.

[17] Tsuji H, Suzuyoshi K. Environmental degradation of biodegradable polyesters 1. Poly( $\varepsilon-$ caprolactone), poly[(R)-3-hydroxybutyrate], and poly(L-lactide) films in controlled static seawater. Polym Degrad Stab 2002;75:347-355.

[18] Tsuji H, Suzuyoshi K. Environmental degradation of biodegradable polyesters 2. Poly( $\varepsilon-$ caprolactone), poly[(R)-3-hydroxybutyrate], and poly(L-lactide) films in natural dynamic seawater. Polym Degrad Stab 2002;75:357-365.

[19] Le Gac PY, Le Saux V, Paris M, Marco Y. Ageing mechanism and mechanical degradation behaviour of polychloroprene rubber in a marine environment: Comparison of accelerated ageing and long term exposure. Polym Degrad Stab 2012;97:288-296.

[20] Le Duigou A, Davies P, Baley C. Seawater ageing of flax/poly(lactic acid) biocomposites. Polym Degrad Stab 2009;94:1151-1162.

[21] Celina M, Gillen KT, Assink RA. Accelerated aging and lifetime prediction: Review of nonArrhenius behaviour due to two competing processes. Polym Degrad Stab 2005;90:395-404.

[22] Davies P, Evrard G. Accelerated ageing of polyurethanes for marine applications. Polym Degrad Stab 2007;92:1455-1464.

[23] Sharqawy MH, Lienhard JH, Zubair SM. Thermophysical properties of seawater: a review of existing correlations and data. Desalination Water Treat 2010;16:354-380.

[24] Arbelaiz A, Fernández B, Ramos JA, Retegi A, Llano-Ponte R, Mondragon I. Mechanical properties of short flax fibre bundle/polypropylene composites: Influence of matrix/fibre modification, fibre content, water uptake and recycling. Compos Sci Technol 2005;65:15821592.

[25] Foulc MP, Bergeret A, Ferry L, Ienny P, Crespy A. Study of hygrothermal ageing of glass fibre reinforced PET composites. Polym Degrad Stab 2005;89:461-470.

[26] Islam MS, Pickering KL, Foreman NJ. Influence of accelerated ageing on the physicomechanical properties of alkali-treated industrial hemp fibre reinforced poly(lactic acid) (PLA) composites. Polym Degrad Stab 2010;95:59-65.

[27] Koo D, Du A, Palmese GR, Cairncross RA. Moisture management of polylactides: The effect of heat treatment. Polymer 2012;53:1115-1123.

[28] Gorrasi G, Pantani R. Effect of PLA grades and morphologies on hydrolytic degradation at composting temperature: Assessment of structural modification and kinetic parameters. Polym Degrad Stab 2013;98:1006-1014. 
[29] Bourmaud A, Riviere J, Le Duigou A, Raj G, Baley C. Investigations of the use of a musselinspired compatibilizer to improve the matrix-fiber adhesion of a biocomposite. Polym Test 2009;28:668-672.

[30] George J, Bhagawan SS, Thomas S. Effects of environment on the properties of low-density polyethylene composites reinforced with pineapple-leaf fibre. Compos Sci Technol 1998;58:1471-1485.

[31] Serpe G, Chaupart N, Verdu J. Ageing of polyamide 11 in acid solutions. Polymer 1997;38:1911-1917.

[32] Gautier L, Mortaigne B, Bellenger V, Verdu J. Osmotic cracking nucleation in hydrothermalaged polyester matrix. Polymer 2000;41:2481-2490.

[33] Pons, Bergeret A, Ferry L, BENEZET JC. Ageing of Biopolymers reinforced by Alterable Glass Fiber, International Committee on Composite Materials, Edinbourg, Scotland: 2009.

[34] Huang Y, Zhang C, Pan Y, Zhou Y, Jiang L, Dan Y. Effect of NR on the hydrolytic degradation of PLA. Polym Degrad Stab 2013;98:943-950.

[35] Codari F, Lazzari S, Soos M, Storti G, Morbidelli M, Moscatelli D. Kinetics of the hydrolytic degradation of poly(lactic acid). Polym Degrad Stab 2012;97:2460-2466.

[36] Grizzi I, Garreau H, Li S, Vert M. Hydrolytic degradation of devices based on poly(dl-lactic acid) size-dependence. Biomaterials 1995;16:305-311.

[37] Burkersroda F von, Schedl L, Göpferich A. Why degradable polymers undergo surface erosion or bulk erosion. Biomaterials 2002;23:4221-4231.

[38] Bellenger V, Ganem M, Mortaigne B, Verdu J. Lifetime prediction in the hydrolytic ageing of polyesters. Polym Degrad Stab 1995;49:91-97.

[39] Jacquemin F, Fréour S, Guillén R. Prediction of local hygroscopic stresses for composite structures - Analytical and numerical micro-mechanical approaches. Compos Sci Technol 2009;69:17-21.

[40] Fukushima K, Tabuani D, Dottori M, Armentano I, Kenny JM, Camino G. Effect of temperature and nanoparticle type on hydrolytic degradation of poly(lactic acid) nanocomposites. Polym Degrad Stab 2011;96:2120-2129.

[41] Li S, McCarthy S. Further investigations on the hydrolytic degradation of poly (DL-lactide). Biomaterials 1999;20:35-44.

[42] Zaidi L, Bruzaud S, Kaci M, Bourmaud A, Gautier N, Grohens Y. The effects of gamma irradiation on the morphology and properties of polylactide/Cloisite 30B nanocomposites. Polym Degrad Stab 2013;98:348-355.

[43] Luo Y-B, Wang X-L, Wang Y-Z. Effect of TiO2 nanoparticles on the long-term hydrolytic degradation behavior of PLA. Polym Degrad Stab 2012;97:721-728.

[44] Paul M-A, Delcourt C, Alexandre M, Degée P, Monteverde F, Dubois P. Polylactide/montmorillonite nanocomposites: study of the hydrolytic degradation. Polym Degrad Stab 2005;87:535-542.

[45] Davies P, Pomiès F, Carlsson LA. Influence of water and accelerated aging on the shear fracture properties of glass/epoxy composite. Appl Compos Mater 1996;3:71-87.

[46] Martin RH. Composite Materials: Fatigue and Fracture. Fifth volume. ASTM International; 1995.

[47] Batzer H, Kreibich UT. Influence of water on thermal transitions in natural polymers and synthetic polyamides. Polym Bull 1981;5:585-590.

[48] Rasselet D, Ruellan A, Guinault A, Miquelard-Garnier G, Sollogoub C, Fayolle B. Oxidative degradation of polylactide (PLA) and its effects on physical and mechanical properties. Eur Polym J 2014;50:109-116.

[49] Fayolle B, Richaud E, Colin X, Verdu J. Review: degradation-induced embrittlement in semicrystalline polymers having their amorphous phase in rubbery state. J Mater Sci 2008;43:6999_ 7012. 
Fig. 1. Evolution of water uptake as function of the square root of immersion time at $50,40,30$ and $25^{\circ} \mathrm{C}$ for PLA samples immerged in distilled water.

Fig. 2. Identification of the diffusion coefficient of distilled water in the PLA for different ageing temperatures.

Fig. 3. Evolution of tensile behaviour of PLA specimens aged in distilled water at 25,30 and $40^{\circ} \mathrm{C}$ after 6 months and at $50^{\circ} \mathrm{C}$ after 15 days, before (a) and after drying (b).

Fig. 4. Evolution of dry mechanical properties of PLA specimens aged in distilled water at 25,30 and $40^{\circ} \mathrm{C}$ after 6 months and at $50^{\circ} \mathrm{C}$ after 15 days: stress at break (a), strain at break (b) and Young modulus (c).

Fig. 5. Evolution of stress at break versus water uptake in distilled water at different temperature.

Fig. 6. SEM micrograph of the fractured surface of unaged PLA (a), of PLA aged in natural seawater (b) and after 6 months immersion at $40^{\circ} \mathrm{C}$ in seawater (c) and distilled water (d). (Red circles show few hole apparition)

Fig. 7. Average number of random chain scissions per unit mass for PLA as a function of immersion time at different temperatures.

Fig.8. Visual aspect before and after the degradation in distilled water (a) and in sea water (b) at different temperatures.

Fig. 9. Comparison between water uptake as a function of square root time at $40^{\circ} \mathrm{C}$ in distilled or seawater (a) and at $25^{\circ} \mathrm{C}$ in distilled or seawater and with natural ageing (b).

Fig. 10. Influence of environment on mechanical tensile behaviour of PLA specimens after 6 months in immersion at 25 and $40^{\circ} \mathrm{C}$ and in immersion in natural seawater, before (a) and after drying (b). 
Table 1. Equilibrium water uptake and Fickian diffusion coefficients for PLA specimens aged in distilled water.

\begin{tabular}{cccc}
\hline $\mathrm{T}\left({ }^{\circ} \mathrm{C}\right)$ & $M_{\infty}(\%)$ & $\mathrm{D} .10^{-7}\left(\mathrm{~cm}^{2} / \mathrm{s}\right)$ & $\mathrm{D}_{\mathrm{c}} \cdot 10^{-7}\left(\mathrm{~cm}^{2} / \mathrm{s}\right)$ \\
\hline $25^{\circ} \mathrm{C}$ & $0.59 \pm 0.03$ & 0.48 & 0.24 \\
$30^{\circ} \mathrm{C}$ & $0.62 \pm 0.03$ & 0.57 & 0.28 \\
$40^{\circ} \mathrm{C}$ & $0.76 \pm 0.03$ & 0.75 & 0.37 \\
$50^{\circ} \mathrm{C}$ & $1.01 \pm 0.02$ & 1.05 & 0.52 \\
\hline
\end{tabular}

Table 2. Mechanical properties of PLA before and after ageing in different aqueous environments and the evolution of properties.

\begin{tabular}{|c|c|c|c|c|c|c|c|c|c|c|}
\hline \multirow[t]{2}{*}{$\mathrm{T}\left({ }^{\circ} \mathrm{C}\right)$} & \multirow{2}{*}{$\begin{array}{l}\text { Immersion } \\
\text { condition }\end{array}$} & \multirow[t]{2}{*}{$\begin{array}{l}\text { Immersion } \\
\text { time (days) }\end{array}$} & \multicolumn{2}{|l|}{$\mathrm{E}(\mathrm{MPa})$} & \multicolumn{3}{|c|}{$\sigma_{\mathrm{b}}(\mathrm{MPa})$} & \multicolumn{3}{|c|}{$\varepsilon_{\mathrm{b}}(\%)$} \\
\hline & & & $3487 \pm 127$ & & 54.7 & $\pm 3,4$ & & 3.4 & $\pm 0,8$ & \\
\hline & $\begin{array}{l}\text { natural ageing } \\
\text { in seawater }\end{array}$ & 180 & $3997 \pm 71$ & $+15 \%$ & 56.9 & $\pm 2,79$ & $+4 \%$ & & $\pm 0,2$ & $-41 \%$ \\
\hline \multirow[t]{2}{*}{25} & distilled water & 180 & $4317 \pm 120$ & $+24 \%$ & 50.2 & $\pm 0,8$ & $-8 \%$ & 6.9 & $\pm 0,8$ & $+103 \%$ \\
\hline & seawater & 180 & $4086 \pm 122$ & $+17 \%$ & 51.4 & $\pm 2,9$ & $-6 \%$ & 5.2 & $\pm 1,2$ & $+53 \%$ \\
\hline 30 & distilled water & 180 & $4068 \pm 132$ & $+17 \%$ & 50.1 & $\pm 1,2$ & $-9 \%$ & & $\pm 0,02$ & $-42 \%$ \\
\hline \multirow[t]{2}{*}{40} & distilled water & 180 & $4032 \pm 125$ & $+16 \%$ & 8 & $\pm 2,5$ & $-85 \%$ & 0.3 & $\pm 0,1$ & $-92 \%$ \\
\hline & seawater & 180 & $4427 \pm 293$ & $+27 \%$ & 16.5 & $\pm 1,9$ & $-70 \%$ & 0.4 & $\pm 0,01$ & $-88 \%$ \\
\hline 50 & distilled water & 15 & $3432 \pm 205$ & $-2 \%$ & 50.3 & $\pm 1,5$ & $-12 \%$ & 1.7 & $\pm 0,03$ & $-50 \%$ \\
\hline
\end{tabular}


Table 3. Evolution of number-average molecular weight $\left(\bar{M}_{\mathrm{n}}\right)$, Cweight-average molecular weight $\left(\bar{M}_{\mathrm{w}}\right)$ and polydispersity index (PI) of PLA samples as a function of temperature in distilled water.

\begin{tabular}{lclll}
\hline $\mathrm{T}\left({ }^{\circ} \mathrm{C}\right)$ & $\begin{array}{c}\text { Immersion } \\
\text { time (days) }\end{array}$ & $\bar{M}_{\mathrm{n}}\left(\mathrm{g} \cdot \mathrm{mol}^{-1}\right)$ & $\bar{M}_{\mathrm{w}}\left(\mathrm{g} \cdot \mathrm{mol}^{-1}\right)$ & PI \\
\hline & 0 & 75000 & 149500 & 1.99 \\
$25^{\circ} \mathrm{C}$ & 180 & 66300 & 132000 & 2.05 \\
$30^{\circ} \mathrm{C}$ & 180 & 64100 & 113000 & 1.81 \\
$40^{\circ} \mathrm{C}$ & 180 & 26400 & 40900 & 1.55 \\
$50^{\circ} \mathrm{C}$ & 30 & 29700 & 46400 & 1.56 \\
\hline
\end{tabular}

Table 4. Evolution of thermal transitions of PLA samples aged in distilled water.

\begin{tabular}{|c|c|c|c|c|c|c|c|c|c|c|c|c|c|}
\hline & \multirow{2}{*}{$\begin{array}{c}\text { Immersion } \\
\text { times } \\
\text { (days) }\end{array}$} & \multicolumn{6}{|c|}{$1^{\text {st }}$ heating } & \multicolumn{6}{|c|}{$2^{\text {nd }}$ heating } \\
\hline & & $\begin{array}{c}\mathrm{T}_{\mathrm{g}} \\
\left({ }^{\circ} \mathrm{C}\right)\end{array}$ & $\begin{array}{c}\mathrm{T}_{\mathrm{cc}} \\
\left({ }^{\circ} \mathrm{C}\right) \\
\end{array}$ & $\begin{array}{l}\Delta \mathrm{H}_{\mathrm{cc}} \\
(\mathrm{J} / \mathrm{g})\end{array}$ & $\begin{array}{c}\mathrm{T}_{\mathrm{m}} \\
\left({ }^{\circ} \mathrm{C}\right) \\
\end{array}$ & $\begin{array}{l}\Delta \mathrm{H}_{\mathrm{m}} \\
(\mathrm{J} / \mathrm{g})\end{array}$ & $\begin{array}{l}\chi_{c} \\
(\%)\end{array}$ & $\begin{array}{c}\mathrm{T}_{\mathrm{g}} \\
\left({ }^{\circ} \mathrm{C}\right)\end{array}$ & $\begin{array}{c}\mathrm{T}_{\mathrm{cc}} \\
\left({ }^{\circ} \mathrm{C}\right) \\
\end{array}$ & $\begin{array}{l}\Delta \mathrm{H}_{\mathrm{cc}} \\
(\mathrm{J} / \mathrm{g})\end{array}$ & $\begin{array}{c}\mathrm{T}_{\mathrm{m}} \\
\left({ }^{\circ} \mathrm{C}\right) \\
\end{array}$ & $\begin{array}{l}\Delta \mathrm{H}_{\mathrm{m}} \\
(\mathrm{J} / \mathrm{g})\end{array}$ & $\begin{array}{c}\chi_{c} \\
(\%)\end{array}$ \\
\hline & unaged & 65 & 126 & 3.1 & 152 & 1.7 & 1.3 & 57 & 126 & 0.8 & 150 & 1.6 & 0.7 \\
\hline $25^{\circ} \mathrm{C}$ & 180 & 60 & 125 & 7 & 155 & 17.1 & 10.8 & 55 & 127 & 9.2 & 153 & 10 & 0.9 \\
\hline $30^{\circ} \mathrm{C}$ & 180 & 58 & 124 & 11 & & 18.8 & 8.4 & 53 & 122 & 13.6 & 149 & 15.8 & 2.4 \\
\hline $40^{\circ} \mathrm{C}$ & 180 & 51 & 92 & 35 & & 36.9 & 2.0 & 51 & 123 & 15.5 & 146 & 17 & 1.6 \\
\hline $50^{\circ} \mathrm{C}$ & 30 & 47 & - & - & 150-155 & 34 & - & 53 & 100 & 29.3 & $147-153^{*}$ & 30.2 & 0.8 \\
\hline
\end{tabular}

${ }^{*}$ Corresponding to a double melting peak 
Table 5. Equilibrium water uptake and Fickian diffusion coefficients for PLA specimens aged in distilled and seawater at different temperature.

\begin{tabular}{lllll}
\hline & & $M_{\infty}(\%)$ & $\mathrm{D} .10^{-7}\left(\mathrm{~cm}^{2} / \mathrm{s}\right)$ & $\mathrm{D}_{\mathrm{c}} \cdot 10^{-7}\left(\mathrm{~cm}^{2} / \mathrm{s}\right)$ \\
\hline \multirow{2}{*}{$25^{\circ} \mathrm{C}$} & natural ageing & $0.47 \pm 0.02$ & 0.37 & 0.18 \\
& distilled water & $0.59 \pm 0.03$ & 0.57 & 0.28 \\
& sea water & $0.52 \pm 0.02$ & 0.54 & 0.26 \\
$40^{\circ} \mathrm{C}$ & distilled water & $0.76 \pm 0.05$ & 0.75 & 0.37 \\
& sea water & $0.74 \pm 0.03$ & 0.73 & 0.36 \\
\hline
\end{tabular}

Table 6. Evolution of number-average molecular weight $\left(\bar{M}_{\mathrm{n}}\right)$, weight-average molecular weight $\left(\bar{M}_{\mathrm{w}}\right)$, and polydispersity index (PI) of PLA samples as a function of aqueous environment.

\begin{tabular}{|c|c|c|c|c|c|}
\hline & & & $\overline{\mathrm{M}}_{\mathrm{n}}\left(\mathrm{g} \cdot \mathrm{mol}^{-1}\right)$ & $\overline{\mathrm{M}}_{\mathrm{w}}\left(\mathrm{g} \cdot \mathrm{mol}^{-1}\right)$ & PI \\
\hline & unaged & 0 & 75000 & 149500 & 1.99 \\
\hline & natural ageing & 180 & 75600 & 141000 & 1.93 \\
\hline \multirow[t]{2}{*}{$25^{\circ} \mathrm{C}$} & distilled water & 180 & 66300 & 132000 & 2.01 \\
\hline & sea water & 180 & 58000 & 127000 & 2.19 \\
\hline \multirow[t]{2}{*}{$40^{\circ} \mathrm{C}$} & distilled water & 180 & 26400 & 40900 & 1.55 \\
\hline & sea water & 180 & 18000 & 35000 & 1.94 \\
\hline
\end{tabular}


Table 7. Evolution of thermal transitions of PLA samples for the natural and accelerated ageing at 25 and $40^{\circ} \mathrm{C}$ after 180 days in immersion.

\begin{tabular}{|c|c|c|c|c|c|c|c|c|c|c|c|c|c|}
\hline & & \multicolumn{6}{|c|}{$1^{\text {st }}$ heating } & \multicolumn{6}{|c|}{$2^{\text {nd }}$ heating } \\
\hline & & $\begin{array}{c}\mathrm{T}_{\mathrm{g}} \\
\left({ }^{\circ} \mathrm{C}\right)\end{array}$ & $\begin{array}{c}\mathrm{T}_{\mathrm{cc}} \\
\left({ }^{\circ} \mathrm{C}\right)\end{array}$ & $\begin{array}{l}\Delta \mathrm{H}_{\mathrm{cc}} \\
(\mathrm{J} / \mathrm{g})\end{array}$ & $\begin{array}{c}\mathrm{T}_{\mathrm{m}} \\
\left({ }^{\circ} \mathrm{C}\right)\end{array}$ & $\begin{array}{l}\Delta \mathrm{H}_{\mathrm{m}} \\
(\mathrm{J} / \mathrm{g})\end{array}$ & $\begin{array}{c}\chi_{c} \\
(\%)\end{array}$ & $\begin{array}{c}\mathrm{T}_{\mathrm{g}} \\
\left({ }^{\circ} \mathrm{C}\right)\end{array}$ & $\begin{array}{c}\mathrm{T}_{\mathrm{cc}} \\
\left({ }^{\circ} \mathrm{C}\right)\end{array}$ & $\begin{array}{l}\Delta \mathrm{H}_{\mathrm{cc}} \\
(\mathrm{J} / \mathrm{g})\end{array}$ & $\begin{array}{c}\mathrm{T}_{\mathrm{m}} \\
\left({ }^{\circ} \mathrm{C}\right)\end{array}$ & $\begin{array}{l}\Delta \mathrm{H}_{\mathrm{m}} \\
(\mathrm{J} / \mathrm{g})\end{array}$ & $\begin{array}{c}\chi_{c} \\
(\%)\end{array}$ \\
\hline & unaged & 65 & 126 & 3.1 & 152 & 1.7 & 1.7 & 57 & 126 & 0.8 & 150 & 1.6 & 0.7 \\
\hline & natural ageing & 61 & 126 & 9.1 & 153 & 11.4 & 2.4 & 54 & 124 & 11.8 & 150 & 13.4 & 1.7 \\
\hline \multirow[t]{2}{*}{$25^{\circ} \mathrm{C}$} & distilled water & 60 & 125 & 6.1 & 155 & 17.1 & 13.5 & 55 & 126 & 9.0 & 153 & 10.4 & 1.7 \\
\hline & seawater & 63 & 126 & 6.4 & 152 & 10.7 & 4.7 & 55 & 126 & 7.8 & 150 & 8.9 & 1.1 \\
\hline \multirow[t]{2}{*}{$40^{\circ} \mathrm{C}$} & distilled water & 51 & 92 & 34.5 & 148 & 36.9 & 2.6 & 51 & 122 & 15 & 146 & 16 & 1.5 \\
\hline & seawater & 62 & 105 & 34.1 & 154 & 35.8 & 1.8 & 51 & 122 & 19.8 & 147 & 21.4 & 1.6 \\
\hline
\end{tabular}




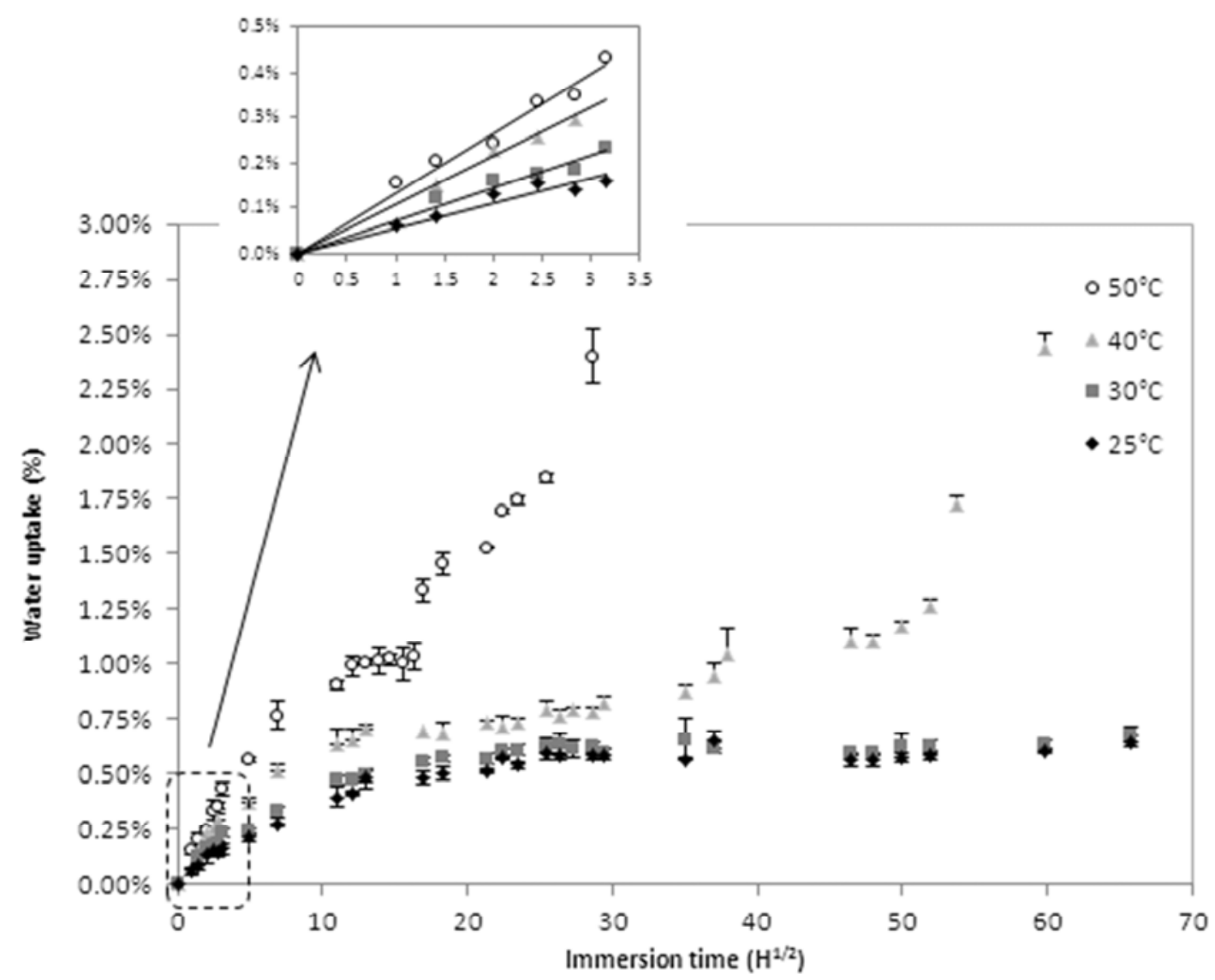




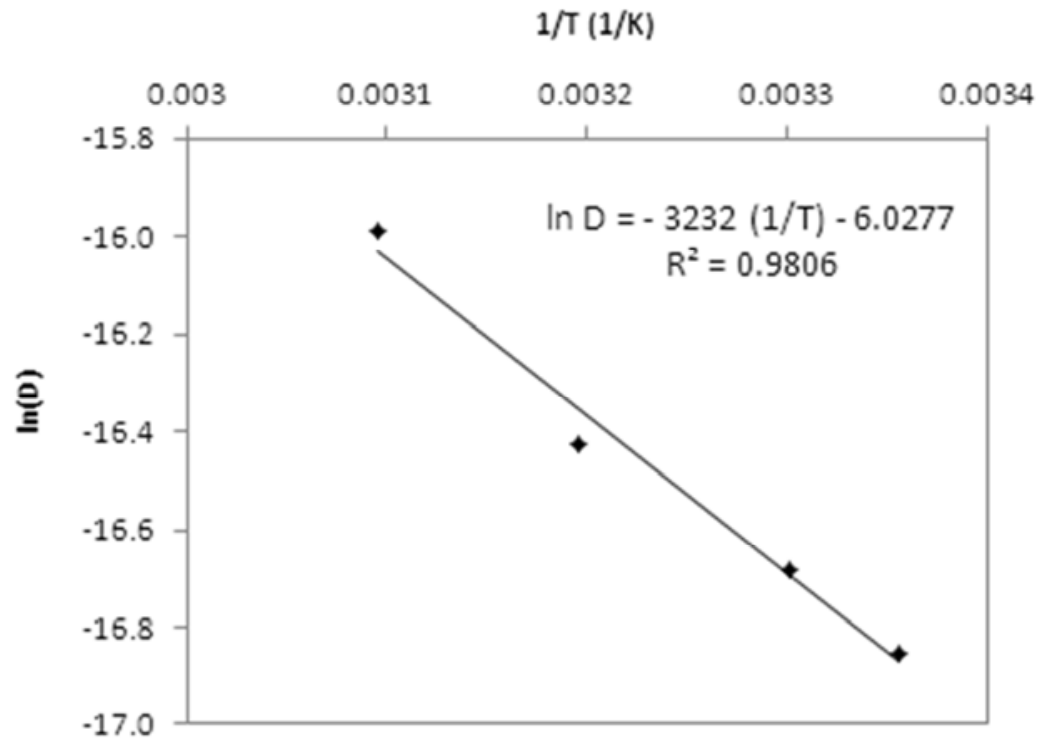



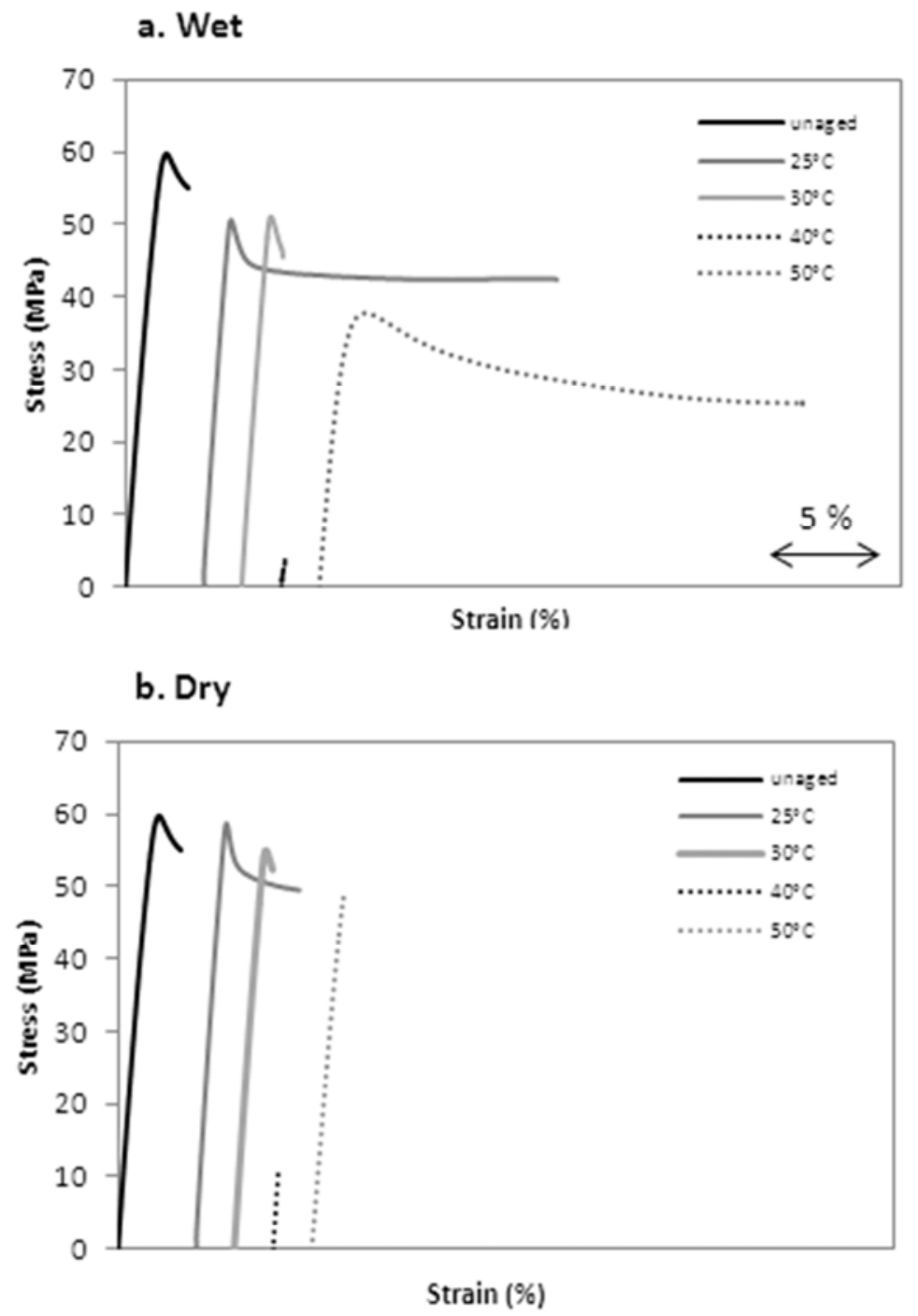


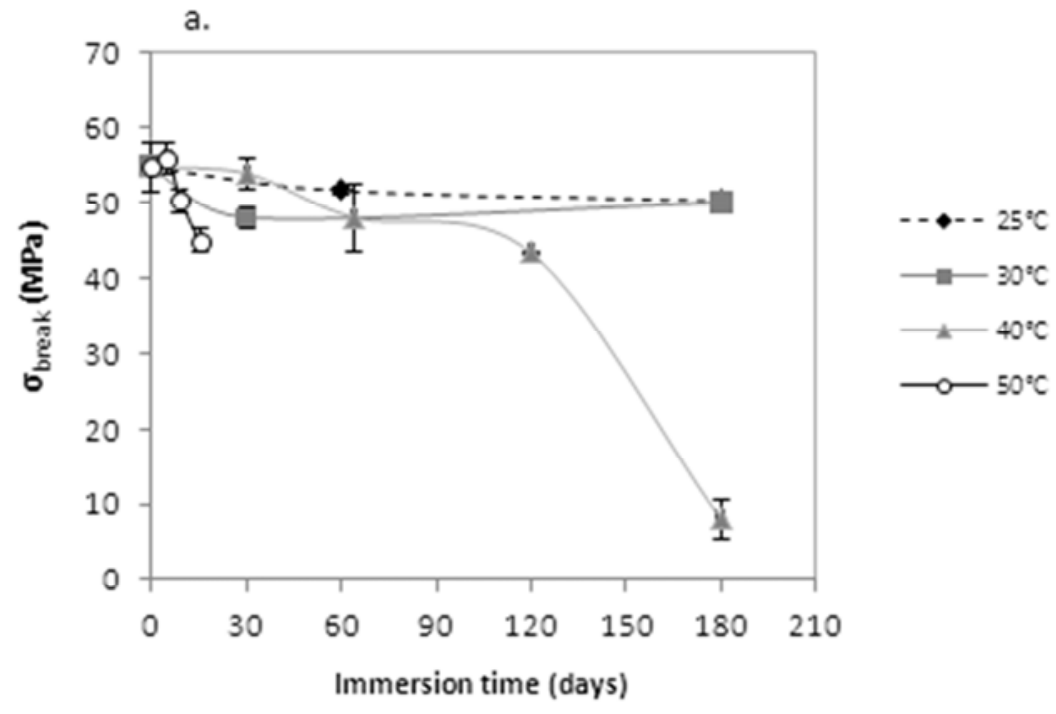




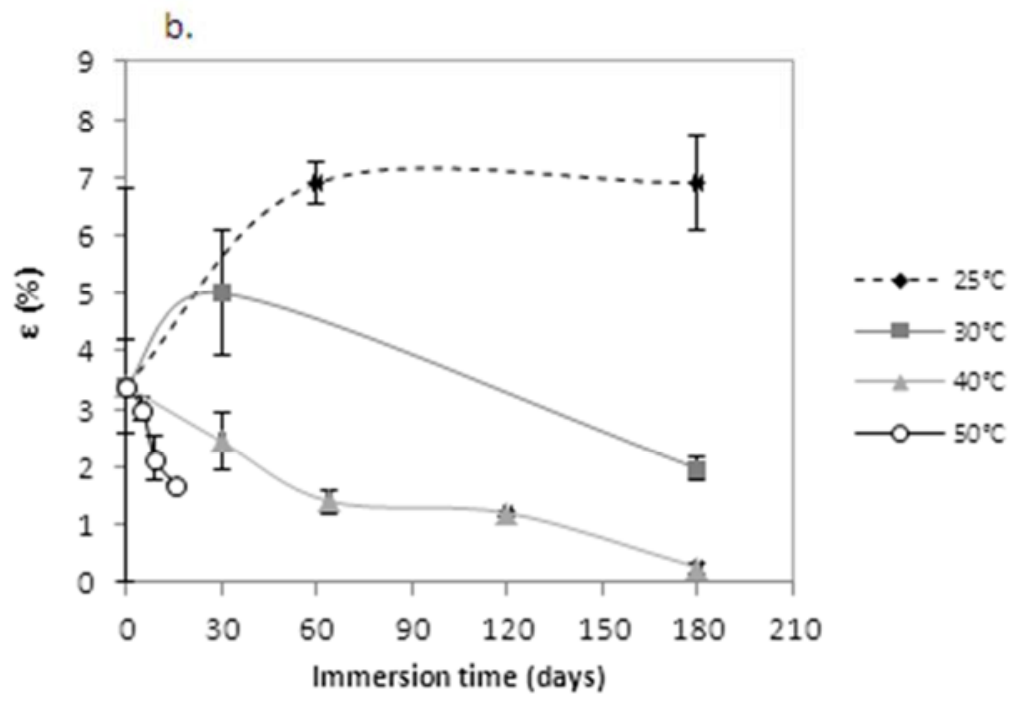




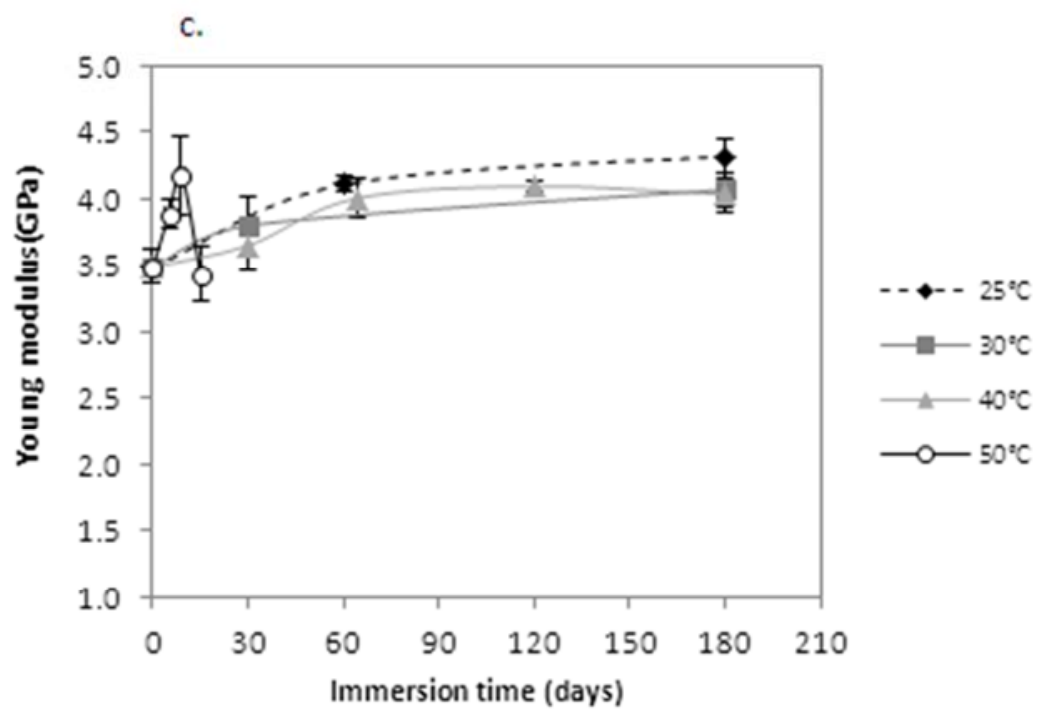




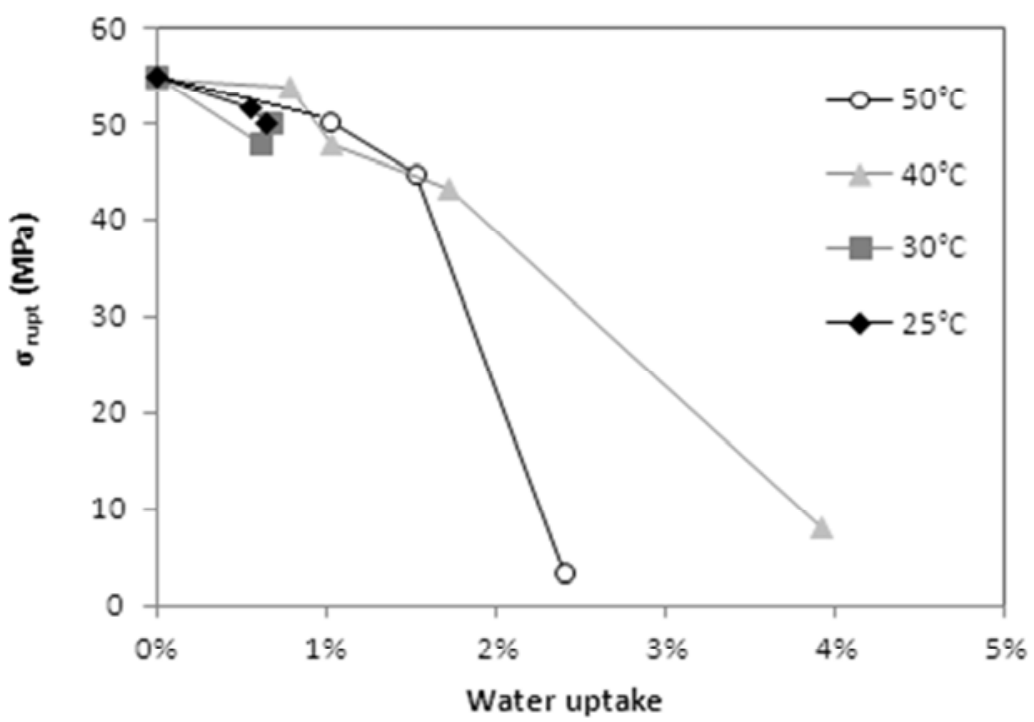



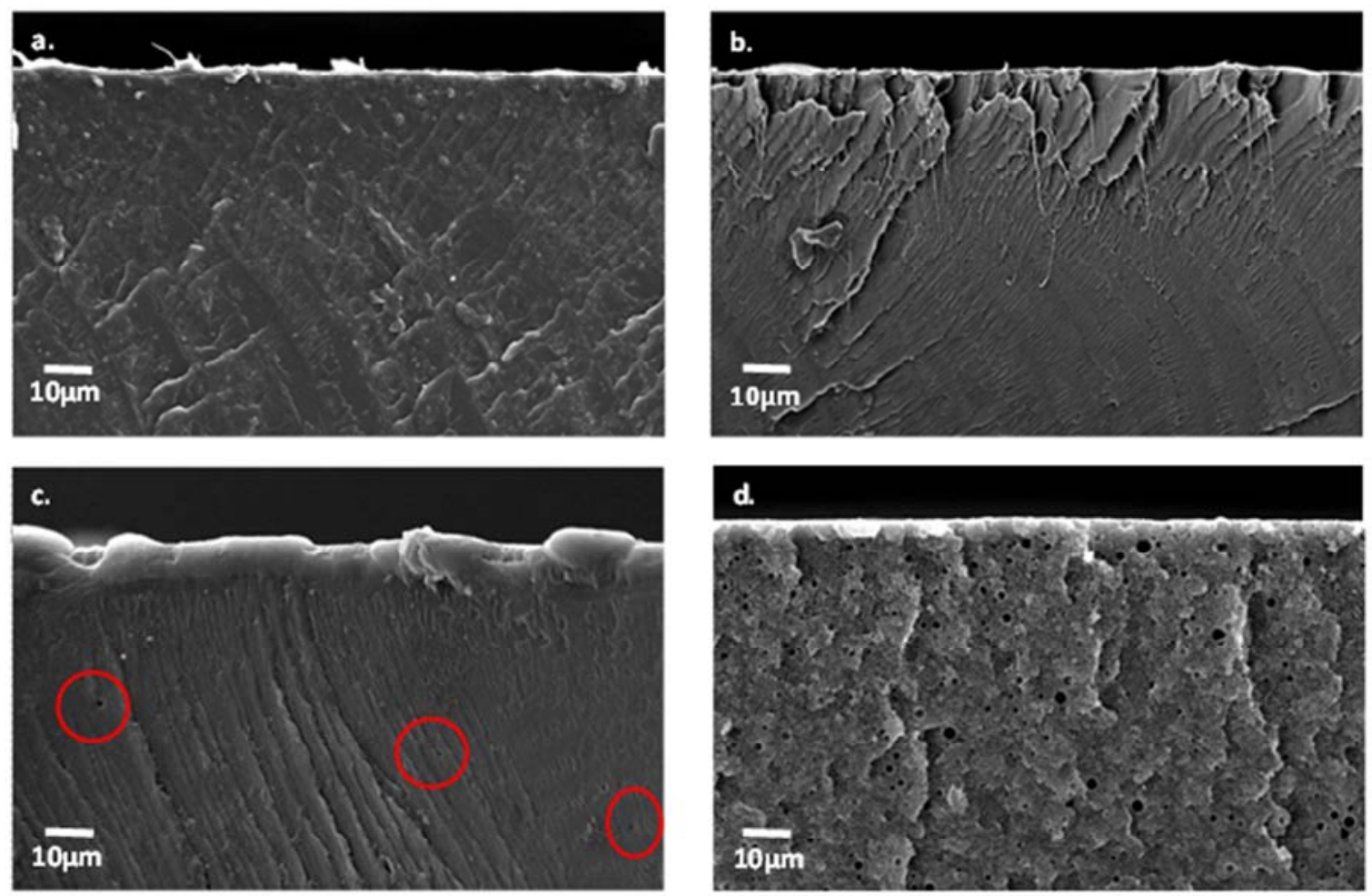


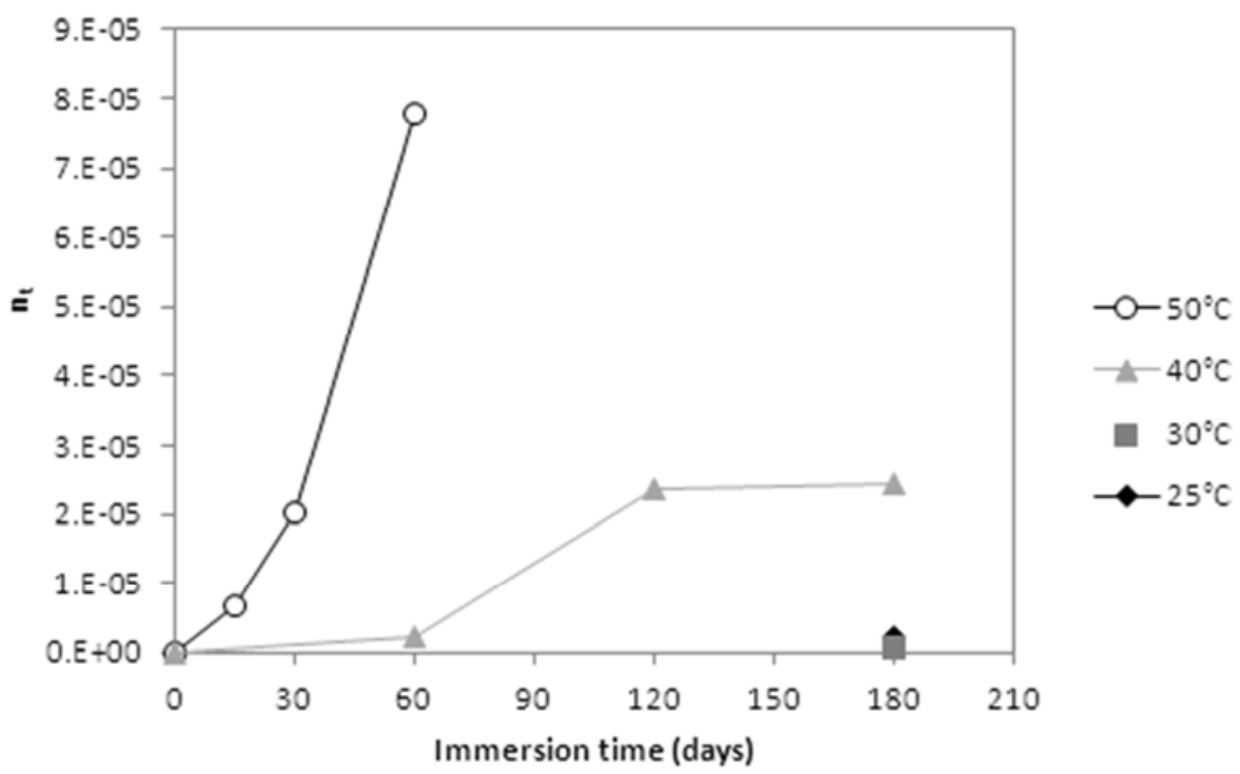




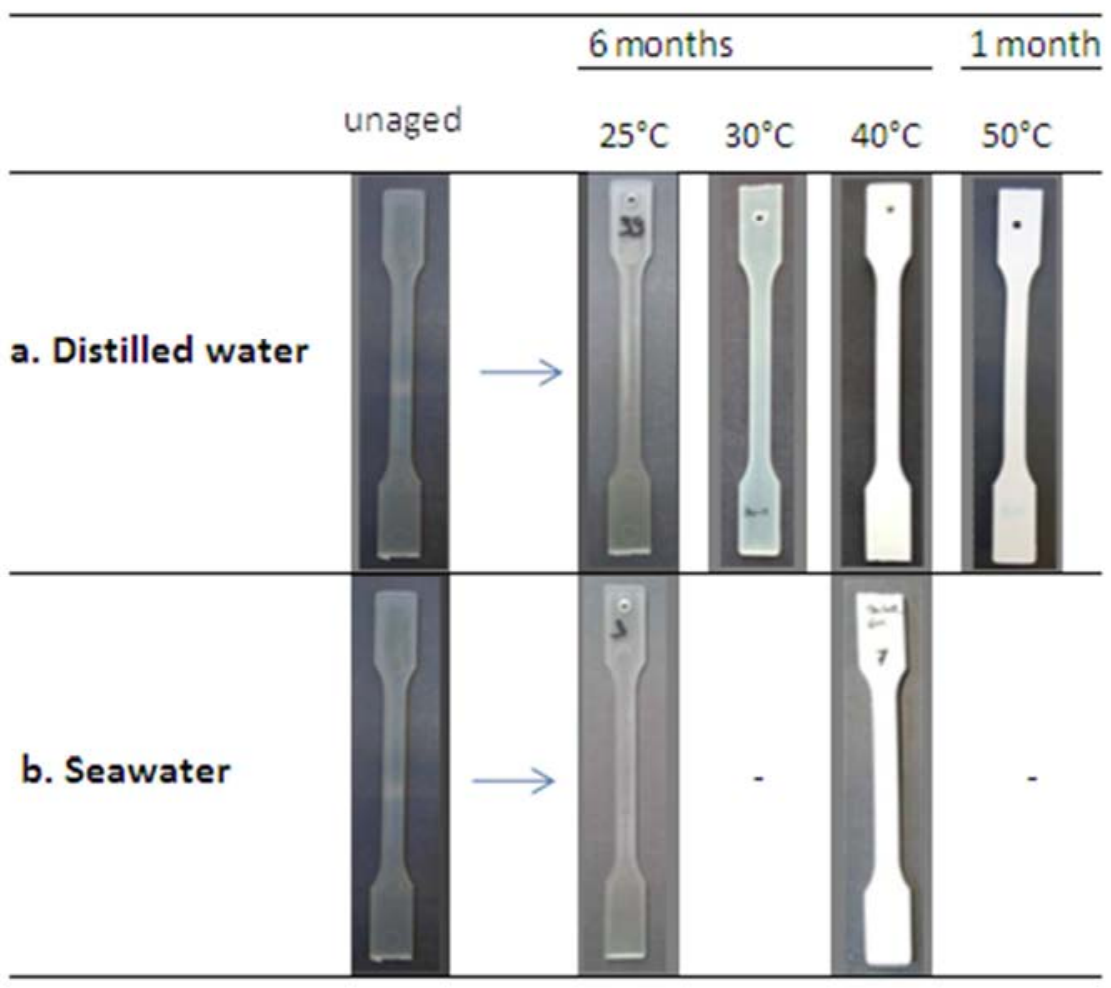



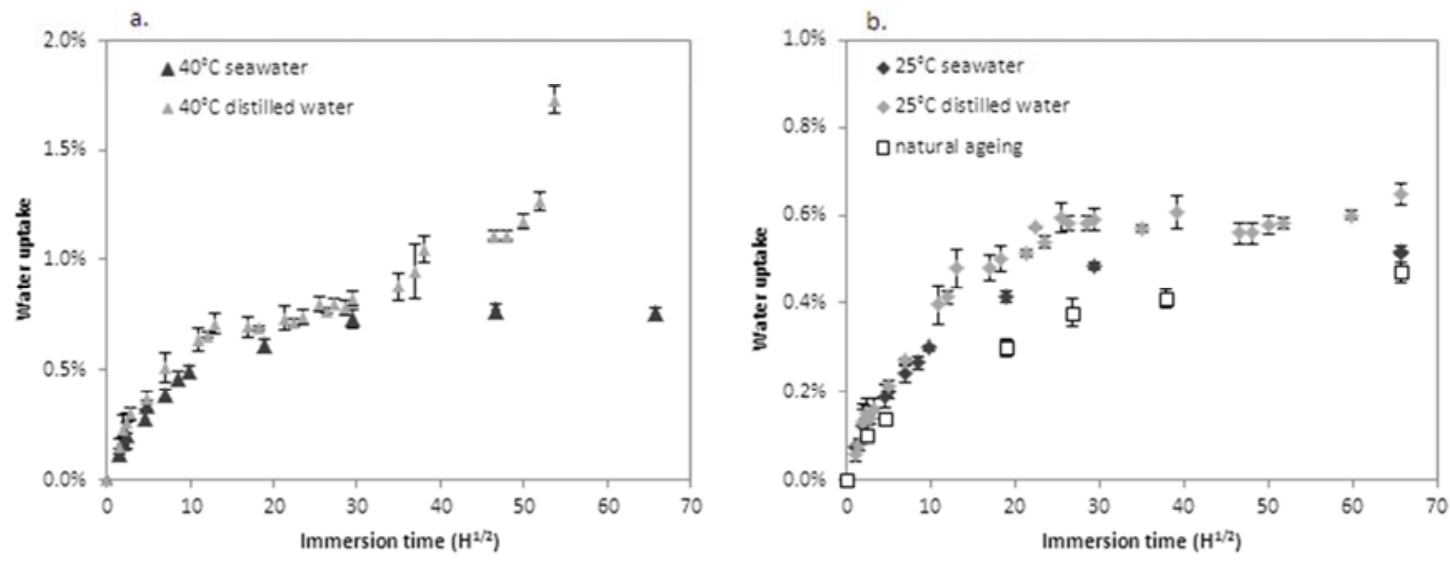
a. Wet

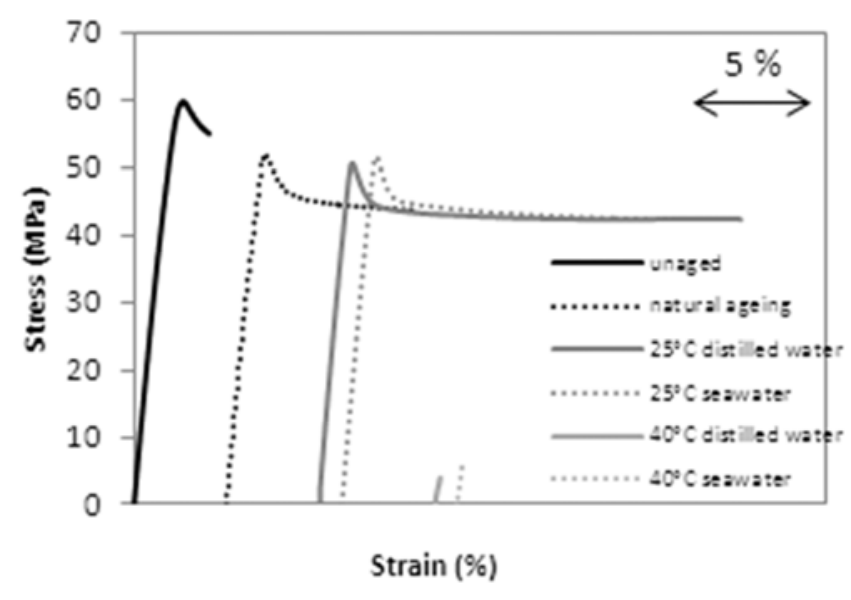

b. Dry

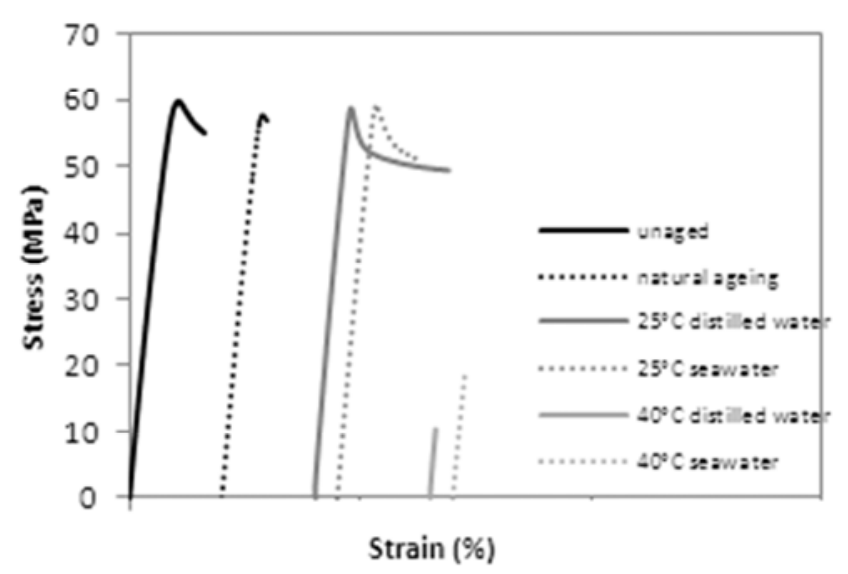

